\title{
On Price Fluctuation in Public Health Crisis
}

\author{
Yiming Zhang \& Xiaona Yuan \\ Department of Economics \\ Dalian University of Technology \\ Dalian 116023, China \\ E-mail: yxnhkc@163.com
}

\begin{abstract}
This thesis focuses on households' response to public health crisis like SARS. A model is proposed to describe households' efforts to reduce the probability of being affected and severity if being affected. The model is expanded considering households' learning process towards the crisis. It is concluded that the government can stabilize the sharp increase in market demands by information release.
\end{abstract}

Keywords: Public health crisis, Price fluctuation, Demands

\section{Introduction}

Recent years have seen several public health crises in China, among which SARS that happened in 2005 is most impressive. The greatest challenge that the government is facing is to take all kinds of measures to prevent the crisis from further spreading and find a more effective medical method to decrease the death rate. However, some chain-reacting problems, for example, the panic among the public from ignorance, dramatic fluctuation of the market, also give the government a rigorous test. This thesis tries to make an analysis in the price fluctuation of concerned commodities in the affair, mainly from the view of demand, but not supply.

In the case of public heath crisis, households will take self-protection measures to decrease the probability of being affected, which results in a sharp increase in demand for self-protection commodities. An enormous gap between demand and supply occurs and instability is caused. In such a case, the government takes three types of measures to stabilize the market. First, ceiling prices for some certain goods are set. Second, those concerned firms are commanded to produce as more as possible to increase the supply. Third, speculations, for example, to make a corner in some goods, release some false information for business promotion, are seriously prohibited. All these measures focus on the supply force. Nevertheless, an in-depth analysis in the households' demands can help the government to understand the problem in an all-round view and solve it more effectively.

As such public heath crisis seldom occurs that we don't take any preliminary measures before, few specific research can be found in this field. However, the existing documentary about environmental risk (Ehrlich and Becker, 1972; Shogren and Crocker, 1991) and preference learning (Hanley, Shogren and White, 1997) is used here for reference.

In section 2, households' decision for self-protection and self-insurance is analyzed in details. It helps to understand and estimate their demands for concerned commodities. In section 3, households' ambiguity towards the disease and measures is considered. In this way, we discuss the problem in a more actual and dynamic view and explain the further changes in market. Section 4 focuses on the role of information, and the measures that the government can take to make the households more rational and adjust their demands.

\section{Households' decision for self-protection and self-insurance}

When SARS or other kinds of heath crisis are proclaimed, individuals or households are urgent to protect themselves from being affected and harmed. In detail, two types of efforts are made:

(1) $S$, ex ante efforts to reduce the probability of being affected, which is defined here as self-protection. In the case of SARS, concerned commodities include masks, disinfectants and disinfectors, etc.

(2) $X$, ex ante efforts to reduce prospective severity if being affected, for example to diminish pains, shorten the 
treatment period, and reduce the probability of death, which is defined as self-insurance. In the case of SARS, concerned commodities include medicinal herbs, some special foods such as radish that help to strengthen one's health, etc.

The household is willing to expend its valuable resources for self-protection and self-insurance. Assume $P_{s}$ and $P_{x}$ are the prices of concerned commodities respectively, which are decided exogenously. $s$ and $x$ are the quantities it buys, which are certainly decided endogenously. Assume $\rho=\rho(s, R)$ is the probability of not being affected. $R$ stands for the level of SARS around. $L=L(x)$ is the money equivalent of realized severity. Then

$$
\begin{gathered}
\rho_{s}=\frac{d \rho}{d s}>0, \quad \rho_{s s}=\frac{d^{2} \rho}{d s^{2}}<0 \\
\rho_{R}=\frac{d \rho}{d R}<0, \quad \rho_{R R}=\frac{d^{2} \rho}{d R^{2}}>0 \\
L_{x}=\frac{d L}{d x}<0, \quad L_{x x}=\frac{d^{2} L}{d x^{2}}>0
\end{gathered}
$$

The household's problem is to select $s$ and $x$ to maximize his expected utility,

$$
\underset{s, x}{\operatorname{aax} E U}=\left[\rho(s, R) U\left(M-s P_{s}-x P_{x}\right)+(1-\rho(s, R)) U\left(M-L(x)-s P_{s}-x P_{x}\right)\right.
$$

where $\mathrm{M}$ is the wealth he owns. The necessary conditions for the household 's optimal levels of self-protection and self-insurance are then

$$
\begin{aligned}
& s: \rho_{s} U\left(M-s P_{s}-x P_{x}\right)-P_{s} \rho(s, R) U_{W}\left(M-s P_{s}-x P_{x}\right) \\
& \quad-\rho_{s} U\left(M-L(x)-s P_{s}-x P_{x}\right)-P_{s}(1-\rho(s, R)) U_{W}\left(M-L(x)-s P_{s}-x P_{x}\right)=0 \\
& x:-P_{x} \rho(s, R) U_{W}\left(M-s P_{s}-x P_{x}\right) \\
& \quad-(1-\rho(s, R)) U_{W}\left(M-L(x)-s P_{s}-x P_{x}\right)\left(P_{x}+L_{x}\right)=0
\end{aligned}
$$

To be simple, assume $U(W)=W, U_{W}=1$, then

$$
\begin{aligned}
& s: \rho_{s} L(x)=P_{s} \\
& x:-(1-\rho) L_{x}=P_{x}
\end{aligned}
$$

In equation (6), $\rho_{s} L(x)$ is the marginal benefit from self-protection, $P_{s}$ is the marginal cost. And in equation (7), $-(1-\rho) L_{x}=(1-\rho)\left|L_{x}\right|$ is the marginal benefit from self-insurance, $P_{x}$ is the marginal cost. In conclusion, the household maximizes expected utility by equating the marginal cost of influencing probability or severity with the marginal benefit acquired.

It can be inferred that,

a. When $\mathrm{L}>>0$ ( $P_{s}$ is constant for the time being), the lost from the disease is rather disastrous, according equation (6), $0<\rho_{s}<<1$; As far as equation (2) concerned, $s>>1$, the household tends to buy large quantities of self-protection commodities. Furthermore, the demand elasticity

$$
E_{s}=\frac{\rho_{s}}{s \cdot \rho_{s s}}(1)
$$

is very small, $\left|E_{s}\right|<<1$. As a result, when the price goes up, the demand quantity will not decline much.

b. When $R>>0$, the disease spreads widely, $0<\rho=\rho(s, R)<<1$. According equation (7), $\left|L_{x}\right|$ must be very small. As far as equation (3) is concerned, $x>>0$. Furthermore, the demand elasticity is very small, $\left|E_{x}\right|<<1$.

Therefore, there will be a sharp increase in demands for those self-protection and self-insurance commodities if it is proclaimed that the disease is fatal and has spread very widely.

\section{Ambiguity, learning and excessive demands}

As the public is unfamiliar with the crisis and even the professionals have not found an effective way to control it, the household does not know exactly how the self-protection and self-insurance measures work. On the other hand, he does 
not know whether the real situation is worse than it has appeared and how it will be in future. In this case, $R, \rho$ and $L$ are ambiguous, and his demands for these commodities are more complex.

Assume the household chooses between two goods, $Q$ and $x$ with a fixed income. $Q$ is an ordinary commodity. $x$ is self-protection or self-insurance commodity. His objective is to maximize his total expected utility - the sum of current utility $U(Q, x)$ and future utility $E U(Q, x), U(\cdot)+\mathrm{EU}(\cdot)$. He knows the utility he will derive from $Q$ but does not know how, if at all, $x$ will offer utility. However, the consumption of $x$ in the first period helps him to increase his expected utility $E U$ in future periods. There are two reasons. (1) He gets information from the consumption about the commodity. For example, when SARS was proclaimed, a variety of goods and measures are recommended to the public. The household does not know which one is more effective, nor the side effects of them. He may get to know this from consumption. So the experiences from first period help him choose from the measures and improve his decision in future periods. It is a process of learning. (2) Self-insurance measures can sustain more than one period. The sooner he takes measures, the better.

Consider the following two kinds of situation.

a. There is only one period. The necessary condition for his optimal levels of $Q$ and $x$ is:

$$
\frac{\partial U}{\partial Q}=\frac{\partial U}{\partial x}
$$

Let $\left(\hat{d}_{Q}, \hat{d}_{x}\right)$ be the solution to the one-period problem. Assume the utility function is concave, then

$$
\begin{aligned}
& \left.\begin{array}{r}
d_{x}<\hat{d}_{x} \\
d_{Q}>\hat{d}_{Q}
\end{array}\right\} \quad \text { if } \quad \partial U / \partial x>\partial U / \partial Q \\
& \left.\begin{array}{rl}
d_{x} & >\hat{d}_{x} \\
d_{Q} & <\hat{d}_{Q}
\end{array}\right\} \quad \text { if } \quad \partial U / \partial x<\partial U / \partial Q
\end{aligned}
$$

b. There are many periods. In the first period, the household will choose $Q$ and $x$ so that

$$
\partial U / \partial Q+\partial E U / \partial Q=\partial U / \partial x+\partial E U / \partial x
$$

Let $\left(\bar{d}_{Q}, \bar{d}_{x}\right)$ be the solution to the multi-period problem. By the previous assumption, $\partial E U / \partial Q=0, \partial E U / \partial x>0$, it follows that $\partial E U / \partial x>\partial E U / \partial Q$. And according equation (12), $\partial U / \partial x<\partial U / \partial Q$. Compared with the one-period problem, from equation (11), we can judge that,

$$
\left\{\begin{array}{l}
\bar{d}_{x}>\hat{d}_{x} \\
\bar{d}_{Q}<\hat{d}_{Q}
\end{array}\right.
$$

The household is willing to pay more for $x$ and less for $Q$ than he would in a one-period problem or in a problem that he is very familiar with, for example, just a typical headache.

Therefore, at the beginning when the crisis is reported, two factors will aggravate people's demands for the concerned commodities: (1) their ambiguity about the disease and protecting measures; (2) the expectation that the hazard will last long. If most people plan to preserve more for future needs, this phenomenon will get much worse. The demands seem to be excessive. Only when the people get more information about the disease and the optional measures they can take, will their demands decline gradually.

\section{The role of information and policy implications}

From the analysis above, four factors are vital to households' consumption decision.

- Threat to be affected.

- Lost if being affected.

- Ambiguity with the disease and optional measures.

- Time the disease will last. 
In this view, information about the disease plays a very important role in the demands fluctuation.

First, information about the disease, its fatalness and spreading situation allows people to make their decision in a rational way. Information control, to prevent bad news from releasing, leads to less self-protection and self-insurance than it should be. On the contrary, panic because of rumors or other reasons leads to excessive demands for self-protection and self-insurance, Figure 1(a), which in turn causes a sharp increase in market prices. Therefore, information releasing from authority can stabilize the market, Figure 1(b).

Second, information about the effectiveness and side effects of the commodities helps people to shorten the process of learning. Households are well aware of the commodities and the amounts they really need in every period, Figure 2 . In this sense, the suppliers should be prohibited to exaggerate the effect of certain goods. The government sector and intermediations can act as information collectors or supervisors.

In summary, the government can stabilize the market by influencing households' demands through information releasing.

\section{Concluding remarks}

In public heath crisis like SARS, there will be a sharp increase in the market demands for concerned commodities. To diminish the market instability, the government tends to pay its attention to market supply. The model in this article helps government to understand households' decision of self-protection and self-insurance, and the learning process when they face a new disease. By releasing sufficient and perfect information, the government can stabilize the market more effectively.

\section{References}

Ehrlich I. and Becker G.(1972), Market Insurance, Self-Insurance, and Self-Protection. Journal of Political Economy, 80, 623-48.

Shogren J.(1990). The Impact of Self-Protection and Self-Insurance on Individual Response to Risk. Journal of Risk and Uncertainty, 3, 191-204.

Shogren J. and Crocker T.(1991). Risk, Self-Protection, and Ex Ante Economic Value. Journal of Environmental Economics and Management, 20, 1-15.

Hanley N., Shogren J. and White B.(1997). Environmental Economics. Macmillan Press Ltd.

Notes

Note 1. According equation (6): $\rho_{s} L(x)=P_{s} \Rightarrow \rho_{s s} L=d P / d s \Rightarrow E_{s}=\frac{d s / s}{d P / P}=\frac{P}{L \rho_{s s} \cdot s}=\frac{\rho_{s}}{s \rho_{s s}}$, it can be inferred from equation (7) that $E_{x}=\frac{L_{x}}{x \cdot L_{x x}}$.
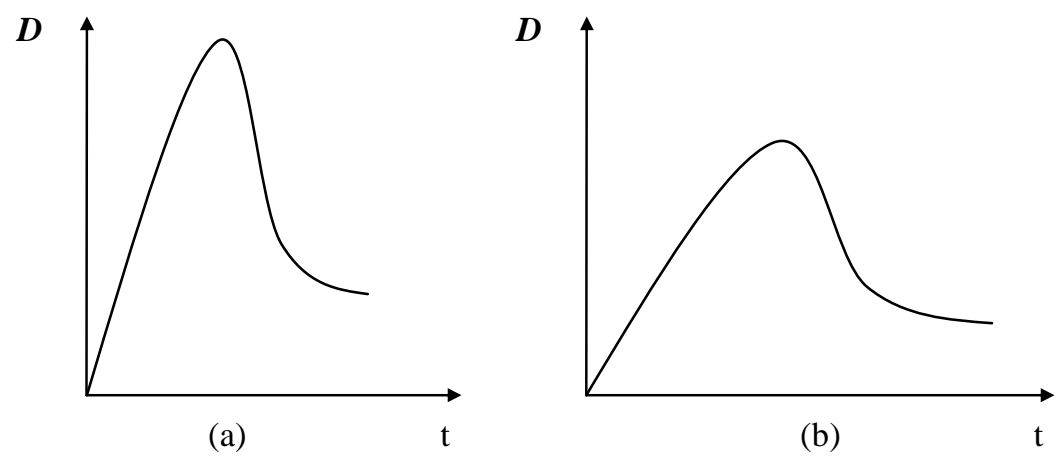

Figure 1. The role of information: rational response 


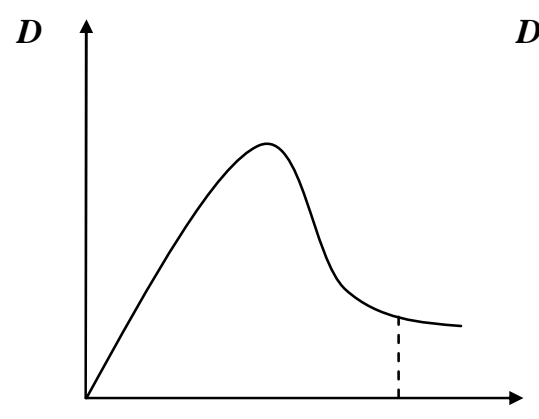

(a)

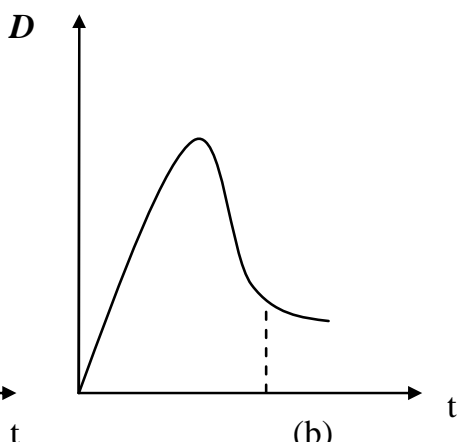

(b)

Figure 2. The role of information: learning process 